\title{
Occult uterine malignancy during laparoscopic supracervical hysterectomy
}

\author{
Iwona Gawron, Krzysztof Skotniczny, Artur Ludwin \\ Department of Gynecology and Oncology, Jagiellonian University, Krakow, Poland
}

\begin{abstract}
Objectives: To estimate the incidence of occult uterine malignancies during laparoscopic supracervical hysterectomy (LSH).

Material and methods: Retrospective cohort study based on archival data (2010-2016) of the Department of Gynecology and Oncology, Jagiellonian University.

Results: Medical records of 696 women, who underwent LSH were analyzed. Two occult sarcomas $(2 / 696 ; 0.29 \%, 0.003$, $95 \% \mathrm{Cl}: 0.001$ to 0.01 ), including one case of low-grade endometrial stromal sarcoma (ESS) with co-occurring atypical endometrial hyperplasia $(\mathrm{AH})$ and one case of high-grade ESS were found postoperatively. One case of invasive primary fallopian tube cancer $(1 / 696 ; 0.14 \%, 0.001,95 \% \mathrm{Cl}: 0.00$ to 0.008$)$ and additional three cases of $\mathrm{AH}(3 / 696 ; 0.57 \%, 0.004$, $95 \% \mathrm{Cl}: 0.001$ to 0.013 ) were also identified. No case of EC was documented. One hundred sixty nine (24.3\%) women of $696 \mathrm{had}$ an endometrial sampling prior LSH including these with ESS. We did not observe worsening of the prognosis and all patients with confirmed malignancy are still alive and free from recurrence in 2-5 years of observations.

Conclusions: Most commonly the occult malignancy would have not been recognized if the surgery had not been conducted. When appropriate diagnostics is conducted, rare incidents of malignant tissue morcellation should not be considered as a professional misconduct but as a possible adverse event. Patients should be informed about the risk of malignancy according to available estimations and that endometrial sampling cannot eliminate such a risk. A consensus regarding safe indications, required diagnostics, and justifiability of mandatory use of contained morcellation for LSH should be developed. Key words: laparoscopic supracervical hysterectomy, power morcellation, occult malignancy
\end{abstract}

Ginekologia Polska 2018; 89, 9: 467-474

\section{INTRODUCTION}

Laparoscopic supracervical hysterectomy (LSH) is an alternative to total laparoscopic hysterectomy (TLH) in the treatment of benign uterine pathologies. LSH is often preferred due to (i) lower invasiveness, easier and faster surgical technique, (ii) sparing the uterus suspension (lower risk of iatrogenic prolapse), (iii) lower risk of other complications (ureteral and bladder damage, infections), (iv) faster recovery, and ( $v$ ) better patient-reported quality-of-life and sexual function compared to TLH [1].

Power morcellation plays a key role in uterine corpus extraction through small incisions within abdominal wall $[2,3]$. During the management of mild uterine disease, there is a risk of missing occult malignancy. In such cases, the patient does not receive proper primary treatment.
Moreover, the morcellation of uterine bodies containing occult malignant tumors may contribute to spreading malignancies [4, 5]. The FDA's April 2014 statement [6, 7], published following the incidental morcellation of the uterine leiomyosarcoma, efficiently supplanted minimally invasive procedures associated with use of power morcellation, including LSH, in the United States (US) $[8,9]$. In other countries, the power morcellation and LSH are commonly performed [10].

The majority of previous studies was related to sarcoma and leiomyosarcoma, and was not focused on any particular procedure, or on other uterine malignancy, such as the most common endometrial cancer (EC), which may be also a subject of non-intentioned power morcellation. Reports from various centers around the world are strictly necessary 
to estimate the real risk justifying the patients' request for these procedures or their refusal.

The main objective of the study was to estimate the incidence of occult uterine malignancies during LSH. Planned secondary aims were: (i) assessment of prognostic factors of occult malignancy based on specific patient characteristic and (ii) impact of occult malignancy on overall prognosis. Finally, we showed our results together with results from available literature.

\section{MATERIAL AND METHODS}

\section{Study design}

Retrospective cohort study was performed with the use of archival data of the Department of Gynecology and Oncology of the Jagiellonian University. The local Bioethics Committee approved the research (No 122.6120.91.217). The search covers procedures performed between 2010 and 2016.

Patient data was obtained both from electronic databases and traditional documentation using medical records encoded according to the International Statistical Classification of Diseases and Related Health Problems (ICD-10) and the International Classification of Medical Procedures (ICD-9). The criterion of inclusion was the qualification to LSH procedure with or without salpingo-oophorectomy. The exclusion criteria were: conversion to laparotomy and conversion to total laparoscopic hysterectomy. Patient demographic and medical data, reported symptoms, ultrasound results, specific histopathological findings and eventual tumor characteristics were obtained from medical records, ultrasound and histopathological results. The incidence of occult malignancies in histopathology results after LSH was counted. The frequency of preoperative endometrial histological verification was evaluated.

\section{Pre-surgical assessment}

Women were examined by specialists in obstetrics and gynecology or gynecological oncology and then qualified for surgical treatment. More than 15 specialists were involved in patients' evaluation within the research period. The gynecological examination with speculoscopy and transvaginal ultrasound was followed by detailed counseling. A cervical PAP test, not older than 1 year, was required before surgery, and colposcopy if needed. If other surgeries (ie. hysteroscopic myomectomy) were considered, sonohysterography with 3D imaging was available as diagnostic tools [11]. All women provided written informed consent to the proposed treatment.

The qualification criteria for LSH were not strictly standardized and reflected individual patient's preference and doctor's suggestions. The lack of local guidelines for the surgical treatment of pathologies suspected of myoma or other benign conditions justified the management based on the best knowledge and experience of a physician. Doctors performed individual assessment of potential malignancy and the justification of endometrial histological verification. Symptomatic patients reporting abnormal uterine bleeding, abdominal pain, compression symptoms or pelvic organ prolapse were intended for surgery. In individually selected cases asymptomatic patients were also directed to surgery, considering the results of gynecological examination and imaging studies, and patients' preference. In the case of abnormal uterine bleeding and/or abnormal ultrasound image of the endometrium, patients were first referred to histological verification of the endometrium (hysteroscopy, Pipelle or D\&C).

\section{Surgery}

Procedures were performed by gynecologists of varied clinical experience and different levels of training in laparoscopy. The surgical technique was consistent throughout the study period, with the exception of management concerning fallopian tubes. A power morcellator (Rotocut G1 and G2 15mm; Karl Storz, Tuttlingen, Germany) was used to shred and remove cut off uterine corps. Methods of contained power morcellation were not used in the study period [12]. Collected tissue material was fixed in $10 \%$ formalin and sent for histopathological examination. In case of macroscopic suspicion of malignant lesion, intraoperative histological verification was available.

\section{Histological examination}

The tissue specimens were evaluated by a specialist pathologist in a tertiary center of pathomorphology (Department of Pathomorphology, Jagiellonian University, Krakow, Poland). In case of diagnostic doubt, experts in the field consulted specimens in order to ensure the highest reliability of histological diagnosis.

\section{Statistical analysis}

Methods of descriptive statistics were used to characterize demographic and clinical data in the study population. Continuous variables were characterized using mean and standard deviations for normal distribution and median, quartile and lower quartiles in all other cases. Maximum and minimum values of variables were also given. Categorical variables were depicted as the number of cases and the percentage. The Wilson method was used for calculation of $95 \%$ confidence intervals (Cls). Statistical analysis was performed using the IBM SPSS v. 23.

\section{RESULTS}

\section{Patients}

During the time period covered by the study, 735 women were qualified to LSH. We excluded 39 (5.3\%) 
patients in whom surgery ended in conversion to other procedures (laparotomy and TLH). Medical records of 696 women, who underwent LSH, with or without salpingo-oophorectomy or salpingectomy, were analyzed. The majority of women $(623 / 696 ; 89.5 \%)$ were at premenopausal age and $73 / 696$ (10.5\%) were postmenopausal. Women who gave birth at least once (614/696) accounted for $88.2 \%$ of the study population and nulliparous (82/696) to $11.8 \%$. Detailed characteristics of the study population like median age, BMI, gravidity, parity are shown in Table 1.

None of the quantitative variables had a normal distribution (in the Kolmogorov-Smirnov test $p<0.01$ ). Median age was 47 years and median body mass index (BMI) was 25 (lower-upper quartile: 22.85-28.04). Median gravidity was 2 (range 1-2) and median parity was also 2 (lower-upper quartile: 1-2). Of ultrasound parameters (Tab. 2), median endometrial thickness was $6 \mathrm{~mm}$ (lower-upper quartile: 4-10) and median biggest fibroid diameter was $40 \mathrm{~mm}$ (lower-upper quartile: $26-52$ ).

With regard to the parameters associated with surgery (Tab. 3), median surgical tissue specimen weight was $140 \mathrm{~g}$ (lower-upper quartile: 83-215). Median pre-operative hemoglobin level was 13g/dl (lower-upper quartile: 11.95-13.7). Median duration of surgery from the start to the end of general anesthesia was 95 minutes (lower-upper quartile:
80-115). Fifteen patients had previously suffered from malignancy (breast cancer in 12 cases, thyroid cancer, hepatic cancer and colon cancer in 1 each).

One hundred sixty nine (24.3\%) women of $696 \mathrm{had}$ an endometrial sampling before LSH. Out of these women, 159 underwent dilation and curettage (D\&C), 5 had an aspiration biopsy (Pipelle), and 5 had hysteroscopy.

The main indication for surgery (Tab. 4), in 629 out of 696 patients $(90.4 \%)$, was symptomatic uterine fibroids, subsequently adenomyosis in 27 patients (3.9\%) and uterine prolapse in 35 patients (5.0\%), appearing separately or in combination. In case of uterine prolapse, the procedure was combined with the suspension of the cervical stump. The most frequently reported symptoms in the study population were heavy menstrual bleeding (440 patients, 63.2\%), irregular menstrual bleeding (77 patients, $11.0 \%$ ), pelvic pain (102 patients, $14.7 \%)$, postmenopausal bleeding (6 patients, $0.9 \%$ ), appearing separately or in combination. Less frequently reported symptoms were discomfort due to uterine prolapse, compression symptoms and urinary incontinence (71 patients, 10.2\%). Ninety-one (13.7\%) patients did not report any symptoms, among them patients with genetic risk of breast and ovarian cancer, and those who wished to undergo surgery due to asymptomatic fibroids.

\begin{tabular}{|c|c|c|c|c|c|c|c|c|c|}
\hline Variable & Mean & $-95 \% \mathrm{Cl}$ & $+95 \% \mathrm{Cl}$ & SD & Min. & Max. & Median & $\begin{array}{l}\text { Lower } \\
\text { quartile }\end{array}$ & $\begin{array}{l}\text { Upper } \\
\text { quartile }\end{array}$ \\
\hline Age & 47.50 & 47.07 & 47.93 & 5.77 & 26.00 & 80.00 & 47.00 & 44.00 & 51.00 \\
\hline BMI & 25.88 & 25.53 & 26.24 & 4.64 & 15.88 & 66.66 & 25.00 & 22.85 & 28.04 \\
\hline Gravidity & 1.86 & 1.78 & 1.94 & 1.09 & 0.00 & 7.00 & 2.00 & 1.00 & 2.00 \\
\hline Parity & 1.72 & 1.64 & 1.79 & 0.99 & 0.00 & 7.00 & 2.00 & 1.00 & 2.00 \\
\hline Hemoglobin & 12.66 & 12.53 & 12.79 & 1.49 & 6.70 & 16.30 & 13.00 & 11.95 & 13.70 \\
\hline
\end{tabular}

\begin{tabular}{l|l|l|l|l|l|l|l|l|l|l|}
\hline Table 2. Endometrium thickness and diameter of presumed myomas \\
\hline Variable & Mean & $\mathbf{- 9 5 \%} \mathbf{~ C l}$ & $\mathbf{+ 9 5 \%}$ Cl & SD & Min. & Max. & Median & $\begin{array}{l}\text { Lower } \\
\text { quartile }\end{array}$ & $\begin{array}{l}\text { Upper } \\
\text { quartile }\end{array}$ \\
\hline Fibroid biggest diameter* & 38.47 & 35.95 & 40.98 & 22.92 & 0.00 & 100.00 & 40.00 & 26.00 & 52.00 \\
\hline Endometrial thickness** & 7.31 & 6.80 & 7.81 & 3.82 & 2.00 & 24.00 & 6.00 & 4.00 & 10.00 \\
\hline
\end{tabular}

${ }^{*} \mathrm{~N}-629 ;{ }^{* *} \mathrm{~N}-696$

\begin{tabular}{|c|c|c|c|c|c|c|c|c|c|}
\hline Variable & Mean & $-95 \% \mathrm{Cl}$ & $+95 \% \mathrm{Cl}$ & SD & Min. & Max. & Median & $\begin{array}{l}\text { Lower } \\
\text { quartile }\end{array}$ & $\begin{array}{l}\text { Upper } \\
\text { quartile }\end{array}$ \\
\hline Tissue weight & 173.16 & 159.17 & 187.16 & 133.67 & 20.00 & 936.00 & 140.00 & 83.00 & 215.00 \\
\hline Duration of surgery* & 99.96 & 97.83 & 102.08 & 28.28 & 35.00 & 245.00 & 95.00 & 80.00 & 115.00 \\
\hline
\end{tabular}

* from the start to the end general anesthesia 
Table 4. Lesions and symptoms associated with indications for surgery

\begin{tabular}{|l|l|}
\hline Lesions/Symptoms & $\mathbf{N}(\%)$ \\
\hline Uterine fibroids & $629(90.37)$ \\
\hline Adenomyosis & $27(3.88)$ \\
\hline Uterine prolapse & $35(5.03)$ \\
\hline Heavy menstrual bleeding & $440(63.22)$ \\
\hline Irregular menstrual bleeding & $77(11.06)$ \\
\hline Pelvic pain & $102(14.66)$ \\
\hline Postmenopausal bleeding & $6(0.86)$ \\
\hline Discomfort due to uterine prolapse, compression symptoms, urinary & $71(10.2)$ \\
\hline Incontinence & $91(13.07)$ \\
\hline No symptoms & \\
\hline
\end{tabular}

Table 5. Intraoperative and early postoperative complications

\begin{tabular}{|l|l|}
\hline Complication & $\mathbf{N}(\%)$ \\
\hline Fragmentation of epiploic appendix & $1(0.14)$ \\
\hline Revision of the surgical field due to hemorrhage & $13(1.87)$ \\
\hline Morcellator failure & $1(0.14)$ \\
\hline
\end{tabular}

Table 6. Occult malignant and precancerous conditions in specimens from LSH

\begin{tabular}{|l|l|}
\hline Histology & $\mathbf{N}(\%)$ \\
\hline Occult malignancy & \\
\hline $\begin{array}{l}\text { Low-grade ESS + AH } \\
\text { High-grade ESS }\end{array}$ & $1(0.14)$ \\
\hline Invasive primary fallopian tube cancer & $1(0.14)$ \\
\hline Precancerous condition & $1(0.14)$ \\
\hline AH & $3(0.43)$ \\
\hline Other & \\
\hline Endometrial hyperplasia without atypia & $16(2.3)$ \\
\hline Atypical myoma & $4(0.6)$ \\
\hline
\end{tabular}

LSH — Laparoscopic supracervical hysterectomy; ESS — Endometrial stromal sarcoma; AH — Atypical endometrial hyperplasia

\section{Adverse events and complications}

One intra-operative complication caused by morcellator was noted (the fragmentation of epiploic appendix). Thirteen (1.9\%) of out 696 patients required revision of the surgical field due to hemorrhage into the abdominal cavity in post-operative course. There was one morcellator failure that resulted in conversion to laparotomy and the patient was excluded (Tab. 5).

\section{Prevalence of malignancy and atypical hyperplasia}

In total, two sarcomas $(2 / 696 ; 0,29 \%, 0.003,95 \% \mathrm{Cl}$ : 0.001 to 0.01 ), including one case of low-grade endometrial stromal sarcoma (ESS) with co-occurring atypical endometrial hyperplasia $(\mathrm{AH})$ and one case of high-grade ESS were found postoperatively (Tab. 6). Interestingly, only the first case concerns the patient with coexisting symptomatic fi- broid, in the second case the indication for LSH was bleeding disorder (heavy menstrual bleeding). One case of invasive primary fallopian tube cancer (1/696; 0.14\%, 0.001, 95\% $\mathrm{Cl}: 0.00$ to 0.008$)$ and additional three cases of $\mathrm{AH}(3 / 696$; $0.57 \%, 0.004,95 \% \mathrm{Cl}: 0.001$ to 0.013 ) were also identified. No case of EC was documented. The patient diagnosed with low-grade sarcoma stromale underwent dilation and curettage (D\&C) 6 months prior to surgery and the patient diagnosed with high-grade endometrial stromal sarcoma had an endometrial aspiration biopsy 3 months before the surgery. Both results showed no endometrial pathology. The patient diagnosed with invasive primary fallopian tube cancer did not have endometrium sampled in preoperative assessment. Two out of three patients with $\mathrm{AH}$ underwent $D \& C$ and the results were unsuspected (hyperplasia without atypia in one case). All three patients diagnosed with malignancy were further directed to second-look laparotomy in 


\begin{tabular}{|c|c|c|c|c|c|c|c|c|}
\hline Date & Age & BMI & HP & $\begin{array}{l}\text { Endometrial } \\
\text { sampling }\end{array}$ & Menopausal st. & Symptoms & Second treatment & ADD. treatment \\
\hline 30.05 .16 & 53 & 28.28 & low-grade ESS & $D \& C$ & pre- & $\mathrm{HMB} / \mathrm{IMB}$ & $\begin{array}{l}\text { Laparotomy. BSO. } \\
\text { Removal of cervix. } \\
\text { Omentectomy. PLND. }\end{array}$ & 0 \\
\hline 28.09 .15 & 42 & 22.04 & high-grade ESS & pipelle & pre- & HMB & $\begin{array}{l}\text { Laparotomy. BSO. } \\
\text { Removal of the } \\
\text { cervix. Omentectomy. } \\
\text { Appendectomy. PLND. }\end{array}$ & 0 \\
\hline 02.10 .12 & 56 & 21.88 & $\begin{array}{l}\text { Adenocarcinoma } \\
\text { serosum of } \\
\text { fallopian tube }\end{array}$ & 0 & post- & POPQ 3 & $\begin{array}{l}\text { Laparotomy. Removal of } \\
\text { the cervix. PLND. }\end{array}$ & Taxol/Carboplatin \\
\hline 19.09.13 & 53 & 27.12 & $\mathrm{AH}$ & $D \& C$ & post- & HMB & $\begin{array}{l}\text { Laparotomy. BSO. } \\
\text { Removal of the cervix. }\end{array}$ & 0 \\
\hline 07.11 .16 & 55 & 23.05 & $\mathrm{AH}$ & 0 & post- & POPQ 3 & $\begin{array}{l}\text { Laparoscopy. Removal of } \\
\text { the cervix. }\end{array}$ & 0 \\
\hline 10.09.15 & 52 & 25.91 & $\mathrm{AH}$ & $D \& C$ & pre- & HMB & Lack of data & - \\
\hline
\end{tabular}

ESS - Endometrial stromal sarcoma; AH - Atypical emdometrial hyperplasia; HMB - Heavy, menstrual bleeding; IMB - Intermenstrual bleeding; BSO — Bilateral salphingoophorectomy; PLND — Plevic lymph node dissection

order to ensure a radical surgical treatment. No dissemination, or other abnormalities in the abdominal cavity were observed in patients who had previously undergone LSH with morcellation of uterine malignancy during a second-look operation.

\section{Impact on prognosis}

Due to the small number of occult malignant tumors, it was not possible to accomplish additional study objectives, i.e. assessment of prognostic factors of occult malignancy and impact of occult malignancy on overall prognosis. However, we did not observe worsening of the prognosis and all patients with confirmed malignancy are still alive and free from recurrence in 2-5 years of observations. Detailed characteristics are shown in Table 7.

\section{Endometrial hyperplasia without atypia and atypical myomas}

Some patients were also diagnosed with other specific lesions: endometrial hyperplasia without atypia (16/696 cases, $2.3 \%)$, leiomyoma cellulare (10/696 patients, $1.4 \%)$, leiomyoma partim cellulare (30/696 patients, $4.3 \%$ ), atypical myoma (4/696 patients, $0.6 \%$ ), leiomyoma bizzare (2/696 patients, $0.29 \%$ ) and adenomyoma (10/696 patients, $1.4 \%)$.

\section{DISCUSSION}

We found three occult malignancies in the cohort of patients who underwent LSH: two uterine sarcomas (low-grade and high-grade ESS) and one case of invasive primary fallopian tube cancer. Both patients with ESS underwent endometrial sampling before surgery. Three other patients had $\mathrm{AH}$, and two of them underwent endometrial sampling, which did not reveal atypical cells.

The study may be vital in modifying the everyday counseling dedicated to patients, who are candidates for LSH, especially regarding informed consent, risk of malignancy, as well as endometrial sampling before surgery. Moreover, the study results that may be unique regarding ethnicity (Caucasians) may support further meta-analyses and local guidelines. Despite potential differences between Polish population and available data form other populations, our study results showed that the presence of undiagnosed uterine malignancy in morcellated specimens is similar (1/348 vs. 1/350) as reported by FDA based on other studies focusing on all laparoscopic procedures with power morcellation [13]. However, it should be noted that FDA focused on uterine sarcomas in women undergoing surgery due to presumed myomas.

Findings from our study indicates that pre-surgical endometrial sampling does not eliminate the occurrence of undetected uterine malignant tumor and precancerous conditions $(\mathrm{AH})$, even in cases considered as detectable in appropriate evaluation, including ultrasound and endometrial sampling [14]. The fact is that $25 \%$ of the patients underwent endometrial sampling, however the two uterine malignancies were found after negative results of endometrial sampling. Thus, patients should be informed about both aspects, i.e. that the risk of morcellation of malignant tissue is present, and that the routine endometrial diagnostic (ultrasound, endometrial sampling) does not exclude the risk of malignancy. It is an open question whether to recommend obligatory pre-operative endometrial sampling. According to recent ESMO-ESGO-ESTRO consensus there are no 
indications to perform the screening of EC in asymptomatic patients [15]. On the other hand, the National Institute for Health and Clinical Excellence (NICE) recommends screening at cancer risk level of 3\% [16]. Most women subjected to $\mathrm{LSH}$ as definitive treatment suffered from myomas and abnormal uterine bleeding (AUB), and most of them were before menopause. In premenopausal women undergoing $D \& C$ due to AUB in our center the incidence of EC is $0.9 \%$ [17]. It seems, that performing endometrial sampling does not seem to be pivotal in all patients destined to undergo LSH. However, the negative result of sampling may be helpful to prevent legal litigation. On the other hand prophylactic endometrial sampling seems scientifically unjustifiable due to the low malignancy prevalence, and should not be considered as obligatory screening before LSH.

In situations where there are specific, yet not strong advantages of LSH in comparison to total laparoscopic or vaginal hysterectomy, the risk and benefits of LSH should be weighed. It is reasonable that LSH should be proposed as an alternative for other minimally invasive procedures without morcellation, i.e. TLH or vaginal hysterectomy (VH), only in patients with very low risk of malignancy.

The weak points of our study are similar to those of the majority of the studies in the field, i.e. retrospective design, specifics of the tertiary and teaching center and population treated [18]. Although a single specific procedure (LSH) was analyzed, results seem to be generalizable, especially when regarding this procedure in the context of local tendencies of qualification given particular symptoms, ultrasound results and size of uteri. Taking into account the above, the true incidence of occult malignancies in all patients who may be considered as candidates for LSH may not coincide with the obtained calculations. The majority of women were operated on due to symptomatic myomas and in the study period LSH was proposed as main option when malignancies were potentially excluded (endometrial sampling) or not suspected on ultrasound, gynecological examination and Pap smear.

The strengths of the research in the context of the presented results are: (i) good quality electronic database of prospectively included all consecutive patients who underwent $\mathrm{LSH}$; (ii) results reflecting real clinical practice with participation of numerous doctors in the treatment process, diagnostic procedures and surgery, that is more generalizable than studies including only experts, and (iii) lack of specific time-dependent changes in diagnostics and procedures associated with FDA restrictions. When thinking about developing the guidelines, it is important to concentrate on cheap and widely available diagnostic tools applicable in the case of typical gynecological symptoms as AUB. MRI was not considered as a diagnostic tool in the evaluation of women with benign diseases, as myomas or adenomyosis in our center, but probably it is performed in other healthcare systems where costs of diagnostics for obvious conditions are less limited.

A few other reports focused on LSH were published (Tab. 8) [19-28]. Some studies have focused only on the incidence of occult leiomyosarcoma, because other malignancies, eg. $\mathrm{EC}$, are considered easy to detect. However, the incidence of undetected morcellated EC may be higher, as was shown in another Polish study [27]. These incidents are a mater of financial compensation to the victims, especially in United States. Although the risk of EC may be higher [28], the accidents of undetected and morcellated cases are an issue of ongoing debates [29].

According to FDA statement power morcellators are contraindicated (i) for removal of tissue, which is known or suspected to contain malignancy, and (ii) in women

Table. 8. Incidence of occult malignancy in studies focused on LSH

\begin{tabular}{|c|c|c|c|c|c|c|c|c|}
\hline Study & year & Study years & Total LSH, n & $\begin{array}{l}\text { Total uterine } \\
\text { malignancy, n (\%) }\end{array}$ & $E C, n(\%)$ & LMS, n (\%) & ESS, n (\%) & other \\
\hline Theben JU et al. [19] & 2013 & $2005-2010$ & 1584 & $4(0.252)$ & $2(0.126)$ & $2(0.126)$ & 0 & 0 \\
\hline Lieng M et al. [20] & 2014 & 2000-2013 & 1846 & $1(0.054)$ & 0 & $1(0.054)$ & 0 & 0 \\
\hline Nugent W et al. [21] & 2015 & 2004-2014 & 14815 & $?$ & $?$ & $16(0.108)$ & $?$ & $?$ \\
\hline Bojahr et al. [22] & 2015 & 1998-2014 & 10731 & $14(0.13)$ & $8(0.075)$ & $2(0.019)$ & $4(0,037)$ & 0 \\
\hline Brown J et al. [23] & 2016 & $2002-2008$ & 778 & $3(0.386)$ & $3(0.386)$ & 0 & 0 & 0 \\
\hline Rodriguez A et al. [24] & 2016 & 2002-2011 & 12226 & $?$ & $?$ & $16(0.131)$ & $?$ & $?$ \\
\hline Perkins RB et al. [25] & 2016 & 2007-2012 & 17903 & $45(0.251)$ & $?$ & $?$ & $?$ & $39(0.218)$ \\
\hline Vallabh-Patel DO et al. [26] & 2016 & 2006-2015 & 786 & $4(0.51)$ & $4(0.51)$ & 0 & 0 & 0 \\
\hline Rechberger T et al. [27] & 2016 & 2011-2015 & 426 & $4(0.94)$ & $3(0.704)$ & 0 & 0 & $1(0.235)$ \\
\hline von Bragen et al. [28] & 2017 & $2007-2014$ & 1044 & 6 & 5 & 0 & 1 & 0 \\
\hline Present study & 2018 & 2010-2016 & 696 & $2(0.29)$ & 0 & 0 & 2 & $1(0.14)$ \\
\hline
\end{tabular}

LSH - Laparoscopic supracervical hysterectomy; EC — Endometrial cancer; ESS — endometrial stromal sarcoma 
with myomas, who are (a) peri- or post-menopausal, or (b) candidates for en bloc tissue removal [30, 31]. Because, the most of women undergoing $\mathrm{LSH}$ with power morcellation may be a candidate for $\mathrm{TLH}, \mathrm{VH}$, and abdominal hysterectomy or myomectomy with en bloc tissue removal, patients should be informed that LSH is not a baseline procedure, and may be associated with higher oncological risk than total hysterectomy. The review of 27 studies from 2014-2016 performed by FDA indicates that laparoscopic morcellation of tissue with occult sarcoma is associated with lowering chances of long-term survival without cancer [31]. A hidden sarcoma may be present in $1 / 225$ to $1 / 580$, and leiomyosarcoma may be present in $1 / 495$ to $1 / 1100$ women undergoing myomas surgery without specification of the procedure type [30, 31].

In our cohort subjected to LSH no occult leiomyosarcoma was found. Occult leiomyosarcoma in women with presumed myomas was the objective of a parallel study in our institution, with partially overlapping population, but focused only on women with myomas and the risk of occult leiomyosarcoma. The estimated incidence was similar to FDA's previous and recent reports [18]. It should be noted that current research, focused on particular procedure (laparoscopy) and its explicit indications, might be a source of publication bias regarding the true prevalence of occult malignancies. However, to show results for LSH individually is justified in terms of raising patients' and healthcare providers' awareness of everyday practice [32]. It should be taken into consideration that in some situations it might be better to make a decision about complete hysterectomy (vaginal, laparoscopic or abdominal) than to insist on sparing the cervix. The summarized data from all studies reporting occult uterine malignancies at LSH are depicted in Table 8. The most frequent occult malignancy was EC, eg. previous Polish study showed the incidence of EC equal to 1:142 [27]. No EC was encountered in our cohort, however 3 cases of $\mathrm{AH}$ were confirmed postoperatively. Including data from our study, the incidence of EC (given studies from Table 8, where EC cases specified) was 1:688 (0.15\%). The incidence of all occult uterine malignancy (given studies from Table 8 , including data from current study) was $1: 433(0.23 \%)$ and in our study $1: 348(0.29 \%)$. Interestingly, one histological specimen from our cohort of LSH revealed fallopian tube cancer. This fact should probably not be treated as complication but rather as an incidental finding, especially since it is difficult to assess what is better - to recognize the disease after morcellation with the risk of spreading malignancy or to diagnose the disease in advanced symptomatic stage during targeted treatment without morcellation.
Although morcellation of occult malignant tumor is considered to be an important complication of $\mathrm{LSH}$, it should be noted that occult malignancy would have not been recognized if the surgery had not been conducted. In conclusion, a consensus regarding obligatory diagnostic before LSH should be developed. If in a patient undergoing appropriate diagnostics, including symptoms, imaging results and histopathological result from an endometrial biopsy (if necessary), undetected malignant tumor will be morcellated, this should not be considered a professional misconduct, but rather as a possible adverse event. All patients should be informed about possibility of such event, and if they do not accept the risk (1/350), LSH should not be performed. Moreover, there are reasonable arguments that LSH should be performed in women, who do not agree to undergo total laparoscopic, vaginal and abdominal hysterectomy as baseline procedures. The boxed warning regarding: (i) the risk of unsuspected malignancy, (ii) the risk of spread of malignant cells, and (iii) and decrease the long-term survival of patients with unsuspected malignancy, who undergo LSH with power morcellation should be included to written informed consent, similarly as is suggested by FDA for women with presumed myomas [31].

On the other hand, the risk of the spreading malignant cells may be lower if all practitioners use contained morcellation [33]. Finally, it would be advisable to ultimately recommend the use of contained morcellation instead of open laparoscopic power morcellation.

\section{CONCLUSIONS}

A consensus regarding safe indications, required pre-operative diagnostics, and justifiability of mandatory use of contained morcellation for LSH should be developed. When appropriate diagnostics is conducted, rare incidents of occult malignant tissue morcellation should not be considered as a professional misconduct but rather as possible adverse event. Patients should be informed about the risk of malignancy according to available estimations and that endometrial sampling cannot eliminate such a risk.

\section{Conflict of interest}

This study received no funding, and the authors have no conflicts of interest to declare.

\section{Acknowledgments}

We thank Professor D. Adamek (Department of Pathomorphology, Jagiellonian University, Cracow, Poland) for their help in accessing the databases.

\section{REFERENCES}

1. Brucker SY, Taran FA, Bogdanyova S, et al. Patient-reported quality-of-life and sexual-function outcomes after laparoscopic supracervical hysterec- 
tomy (LSH) versus total laparoscopic hysterectomy (TLH): a prospective, questionnaire-based follow-up study in 915 patients. Arch Gynecol Obstet. 2014; 290(6): 1141-1149, doi: 10.1007/s00404-014-3318-1, indexed in Pubmed: 24973868.

2. Steiner RA, Wight E, Tadir Y, et al. Electrical cutting device for laparoscopic removal of tissue from the abdominal cavity. Obstet Gynecol. 1993; 81(3): 471-474, indexed in Pubmed: 8437807.

3. Carter JE, McCarus SD. Laparoscopic myomectomy. Time and cost analysis of power vs. manual morcellation. J Reprod Med. 1997; 42(7): 383-388, indexed in Pubmed: 9252927.

4. Pritts EA, Parker WH, Brown J, et al. Outcome of occult uterine leiomyosarcoma after surgery for presumed uterine fibroids: a systematic review. J Minim Invasive Gynecol. 2015; 22(1): 26-33, doi: 10.1016/j. jmig.2014.08.781, indexed in Pubmed: 25193444.

5. Seidman MA, Oduyebo T, Muto MG, et al. Peritoneal dissemination complicating morcellation of uterine mesenchymal neoplasms. PLoS One. 2012; 7(11): e50058, doi: 10.1371/journal.pone.0050058, indexed in Pubmed: 23189178.

6. FDA. Laparoscopic uterine power morcellation in hysterectomy and myomectomy: FDA safety communication. https://www.basg. gv.at/fileadmin/_migrated/content_uploads/FDA_Safety_Communication_Laparoscopic_Morcellation_Hysterectomy.pdf.

7. Brower V. FDA considers restricting or banning laparoscopic morcellation. J Natl Cancer Inst. 2014; 106(10), doi: 10.1093/jnci/dju339, indexed in Pubmed: 25313228.

8. Ottarsdottir H, Cohen SL, Cox M, et al. Trends in Mode of Hysterectomy After the U.S. Food and Drug Administration Power Morcellation Advisory. Obstet Gynecol. 2017; 129(6): 1014-1021, doi: 10.1097/AOG.0000000000002058, indexed in Pubmed: 28486371.

9. Multinu F, Casarin J, Hanson KT, et al. Practice Patterns and Complications of Benign Hysterectomy Following the FDA Statement Warning Against the Use of Power Morcellation. JAMA Surg. 2018; 153(6): e180141, doi: 10.1001/jamasurg.2018.0141, indexed in Pubmed: 29641835.

10. Halaska MJ, Haidopoulos D, Guyon F, et al. ESGO Council. European Society of Gynecological Oncology Statement on Fibroid and Uterine Morcellation. Int J Gynecol Cancer. 2017; 27(1): 189-192, doi: 10.1097/IGC.0000000000000911, indexed in Pubmed: 28002210.

11. Ludwin A, Ludwin I, Pityński K, et al. Transrectal ultrasound-guided hysteroscopic myomectomy of submucosal myomas with a varying degree of myometrial penetration. J Minim Invasive Gynecol. 2013; 20(5): 672-685, doi: 10.1016/j.jmig.2013.05.001, indexed in Pubmed: 23850363.

12. Clark NV, Cohen SL. Tissue Extraction Techniques During Laparoscopic Uterine Surgery. J Minim Invasive Gynecol. 2018; 25(2): 251-256, doi: 10.1016/j.jmig.2017.07.030, indexed in Pubmed: 28866098.

13. FDA. Quantitative Assessment of the Prevalence of Unsuspected Uterine Sarcoma in Women Undergoing Treatment of Uterine Fibroids, Food Drug Adm 2014. https://www.fda.gov/downloads/medicaldevices/safety/alertsandnotices/ucm393589.pdf.

14. Tissue Extraction Task Force Members. Electronic address: generalmail@aagl.org. Morcellation during Uterine Tissue Extraction: An Update. J Minim Invasive Gynecol. 2018; 25(4): 543-550, doi: 10.1016/j. jmig.2018.03.010, indexed in Pubmed: 29581072.

15. Colombo N, Creutzberg $C$, Amant $\mathrm{F}$, et al. ESMO-ESGO-ESTRO Endometrial Consensus Conference Working Group. ESMO-ESGO-ESTRO Consensus Conference on Endometrial Cancer: diagnosis, treatment and follow-up. Ann Oncol. 2016; 27(1): 16-41, doi: 10.1093/annonc/mdv484, indexed in Pubmed: 26634381.

16. Emery J, Vedsted P. New NICE guidance on diagnosing cancer in general practice. Br J Gen Pract. 2015; 65(638): 446-447, doi: 10.3399/bjgp15X686401, indexed in Pubmed: 26324471.

17. Gawron I, Łoboda M, Babczyk D, et al. Endometrial cancer and hyperplasia rate in women before menopause with abnormal uterine bleeding undergoing endometrial sampling. Przegl Lek. 2017; 74(4): 139-43., indexed in Pubmed: 29696944.
18. Ludwin A, Gawron I, Pityński K. Occult uterine leiomyosarcoma in women undergoing abdominal and minimally invasive surgeries for myomas. Ginekol Pol.; 2018. [Accepted for publication].

19. Theben JU, Schellong ARM, Altgassen C, et al. Unexpected malignancies after laparoscopic-assisted supracervical hysterectomies (LASH): an analysis of 1,584 LASH cases. Arch Gynecol Obstet. 2013; 287(3): 455-462, doi: 10.1007/s00404-012-2559-0, indexed in Pubmed: 23053310.

20. Lieng $M$, Berner $E$, Busund B. Risk of morcellation of uterine leiomyosarcomas in laparoscopic supracervical hysterectomy and laparoscopic myomectomy, a retrospective trial including 4791 women. J Minim Invasive Gynecol. 2015; 22(3): 410-414, doi: 10.1016/j.jmig.2014.10.022, indexed in Pubmed: 25460521.

21. Nugent W, Engelke G, Reicke $S$, et al. Laparoscopic Supracervical Hysterectomy or Myomectomy With Power Morcellation: Risk of Uterine Leiomyosarcomas. A Retrospective Trial Including 35.161 Women in Germany. J Minim Invasive Gynecol. 2015; 22(6S): S2-S3, doi: 10.1016/j. jmig.2015.08.013, indexed in Pubmed: 27679029.

22. Bojahr B, De Wilde RL, Tchartchian G. Malignancy rate of 10,731 uteri morcellated during laparoscopic supracervical hysterectomy (LASH). Arch Gynecol Obstet. 2015; 292(3): 665-672, doi: 10.1007/s00404-0153696-z, indexed in Pubmed: 25820974.

23. Brown J, Taylor K, Ramirez PT, et al. Laparoscopic supracervical hysterectomy with morcellation: should it stay or should it go? J Minim Invasive Gynecol. 2015; 22(2): 185-192, doi: 10.1016/j.jmig.2014.09.005, indexed in Pubmed: 25242233.

24. Rodriguez AM, Zeybek B, Asoglu MR, et al. Incidence of occult leiomyosarcoma in presumed morcellation cases: a database study. Eur J Obstet Gynecol Reprod Biol. 2016; 197: 31-35, doi: 10.1016/j. ejogrb.2015.11.009, indexed in Pubmed: 26699101.

25. Perkins RB, Handal-Orefice R, Hanchate AD, et al. Risk of Undetected Cancer at the Time of Laparoscopic Supracervical Hysterectomy and Laparoscopic Myomectomy: Implications for the Use of Power Morcellation. Womens Health Issues. 2016; 26(1): 21-26, doi: 10.1016/j. whi.2015.09.008, indexed in Pubmed: 26701205.

26. Vallabh-Patel V, Saiz C, Salamon C, et al. Prevalence of Occult Malignancy Within Morcellated Specimens Removed During Laparoscopic Sacrocolpopexy. Female Pelvic Med Reconstr Surg. 2016; 22: 420-42.

27. Rechberger $T$, Miotła $\mathrm{P}$, Futyma $\mathrm{K}$, et al. Power morcellation for women undergoing laparoscopic supracervical hysterectomy safety of procedure and clinical experience from 426 cases. Ginekol Pol. 2016; 87(8): 546-551, doi: 10.5603/GP.2016.0042, indexed in Pubmed: 27629127.

28. Von Bargen EC, Grimes CL, Mishra K, et al. Prevalence of occult pre-malignant or malignant pathology at the time of uterine morcellation for benign disease. Int J Gynaecol Obstet. 2017; 137(2): 123-128, doi: 10.1002/ijgo.12111, indexed in Pubmed: 28170091.

29. Parsons $L H$, Pedersen R, Richardson DL, et al. The prevalence of occult endometrial cancer in women undergoing hysterectomy for benign indications. Eur J Obstet Gynecol Reprod Biol. 2018; 223: 108-112, doi: 10.1016/j.ejogrb.2018.02.017, indexed in Pubmed: 29518640.

30. FDA. Laparoscopic Power Morcellators. https://www.fda. gov/medicaldevices/productsandmedicalprocedures/surgeryandlifesupport/ucm584463.htm.

31. FDA. Updated Assessment of The Use of Laparoscopic Power Morcellators to Treat Uterine Fibroids December 2017. https://www.fda. gov/downloads/MedicalDevices/ProductsandMedicalProcedures/SurgeryandLifeSupport/UCM584539.pdf.

32. Mowers EL, Lim CS, Skinner B, et al. Patients'Knowledge and Perceptions of Morcellation. JSLS. 2017; 21(3), doi: 10.4293/JSLS.2017.00009, indexed in Pubmed: 28694681.

33. Cohen $\mathrm{SL}$, Hariton E, Afshar Y, et al. Updates in uterine fibroid tissue extraction. Curr Opin Obstet Gynecol. 2016; 28(4): 277-282, doi: 10.1097/GCO.0000000000000280, indexed in Pubmed: 27253236. 